NIST Economic Analysis Briefs 4

\title{
The Economic Impact of Technology Infrastructure for Smart Manufacturing
}

\author{
Gary Anderson (gary.anderson@nist.gov) \\ Technology Partnerships Office, Innovation \& Industry Services
}

\section{Key Findings}

October 2016

- Novel smart manufacturing technology infrastructure would save manufacturers $\$ 57.4$ billion annually.

- Barriers to innovation increase the cost of smart manufacturing R\&D, weaken private investment incentives, and magnify the role of public institutions.

- Overcoming critical technical barriers may require investments in public-private manufacturing consortia.

- Small enterprises face significant barriers to adoption of smart manufacturing technology.

Figure 1: Overview of Smart Manufacturing

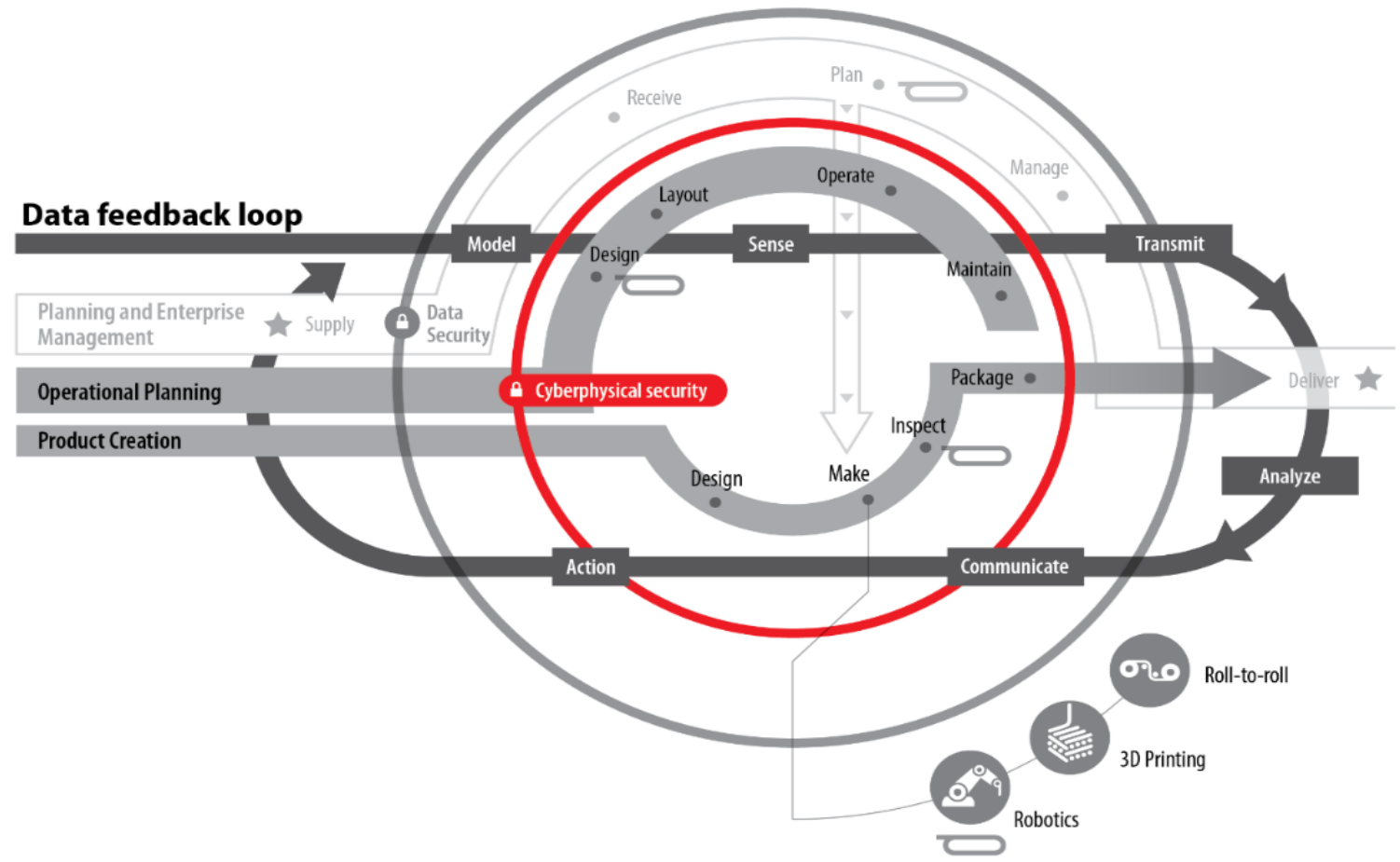

Introduction

Smart manufacturing processes use digital information to optimize product, factory, and supply-chain operations. Advances in sensing, communicating, and analyzing digital information have introduced a vast array of new opportunities for increasing efficiency, lowering costs, and improving quality. However, a recent study ${ }^{1}$ commissioned by the National Institute of Standards and Technology (NIST) finds that while prior research contains little "agreement on why [smart manufacturing] is not being

NLT

National Institute of Standards and Technology
U.S. Department of Commerce 
adopted at a faster rate in key manufacturing sectors of the U.S. economy." In fact "barriers exist to the adoption of all but the simplest of smart manufacturing technologies. Enhancements in the technology infrastructure are needed to develop next-generation smart manufacturing technologies." Technology infrastructure ${ }^{2}$ includes a broad array of public and quasi-public technologies and technical knowledge. That infrastructure can support the research, development, production, and diffusion activities taking place at national laboratories, universities and firms alike.

The unique contribution of this analysis is the identification of barriers to the adoption of smart manufacturing technology and estimation of the impact of eliminating these barriers. Based on over 80 in-depth interviews and an extensive review of prior studies, the analysis identifies six critical gaps in smart manufacturing capabilities and the specific technology infrastructure needed to close those gaps. Table 1 identified these gaps. The analysis reflects the insights of stakeholders throughout the entire manufacturing supply chain including smart manufacturing equipment developers, smart manufacturing service providers, and manufacturers, as well as stakeholders in research organizations and industry associations. Table 1 details the critical gaps identified in this analysis and identifies the potential economic benefits of meeting these needs. Meeting these needs offers an array of opportunities to expand capabilities, improve product quality, reduce costs and cut the time to introduce innovative products, services and processes to the market.

The analysis estimates that meeting these needs would save manufacturing companies $\$ 57.4$ billion annually. Figure 2 shows the projected impacts of meeting each identified need. Enhanced sensing and monitoring, seamless transmission of digital information, and advances in analyzing data and trends each has the potential to save manufacturers in excess of $\$ 10$ billion annually. There are slightly lower annual benefits associated with meeting needs in the following areas: determining and implementing required actions; managing digital data through models; and efficient communication of information to decision makers.

Figure 2: Total Annual Impact, Apportioned by Technology Need (Millions of 2013 US\$)

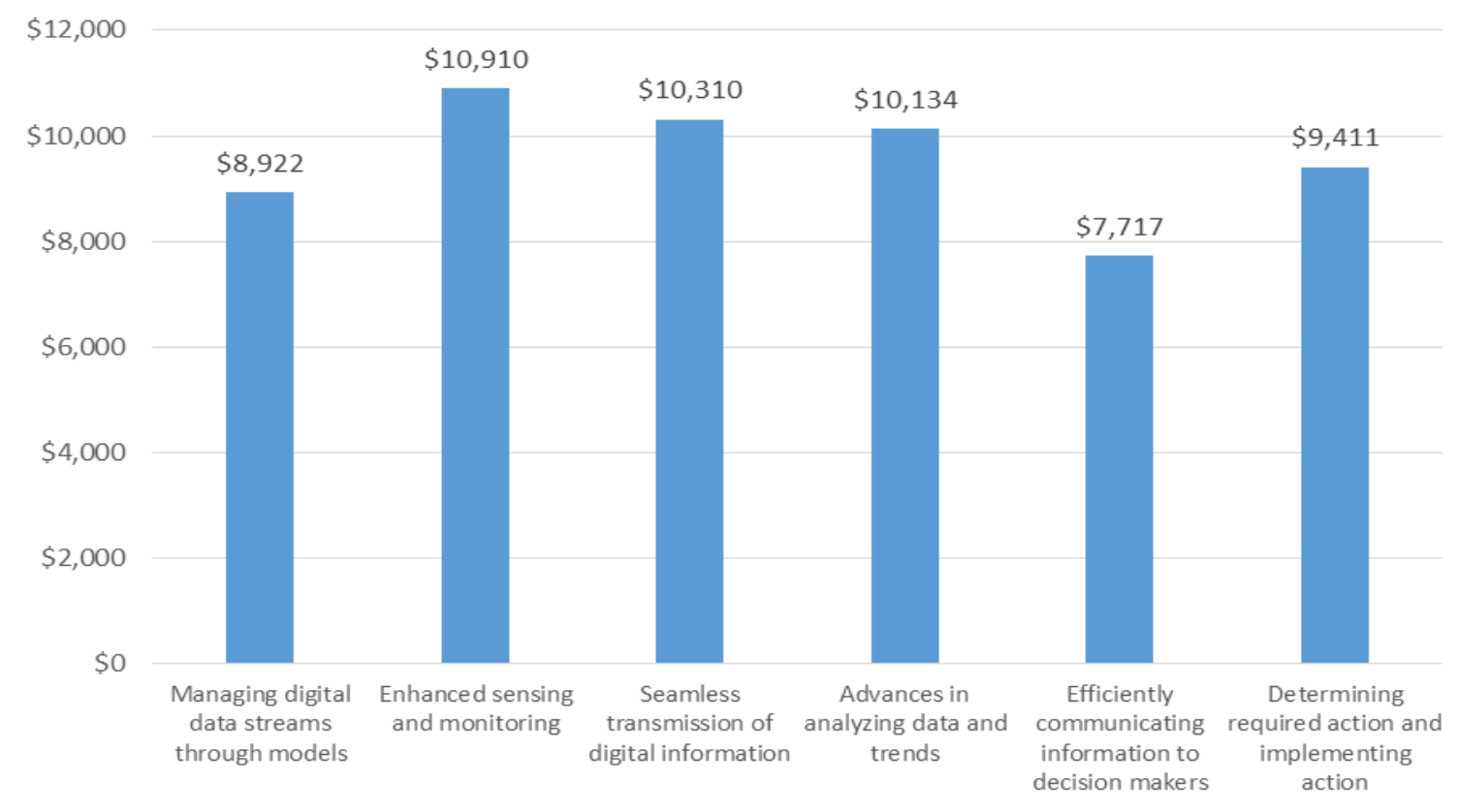


Table 1. Capabilities, Needs and Potential Impacts

\section{Smart Manufacturing Capabilities}

Managing digital data streams through models:

- CAD models including material characteristics,

- simulation models of part creation and plant layout

- rapid automated costing functions

\section{Technology Infrastructure Needed to Support Capabilities}

High-fidelity process models, physical model representation for flexible objects, simplified modular applications of CAM software for less sophisticated uses, data standardization, standard and simpler equipment interfaces to facilitate consistent data entry for less-skilled workers, standard terminology for automated part costing

In-process measuring and monitoring for physical processes, self-powered sensors, robust sensors to withstand harsh manufacturing processes, data standardization, methods for calibrating sensing and monitoring systems

Potential Benefits and Impacts of Enhanced Technology Infrastructure

- Ability to capture featurebased information in design models

- Streamlined simulation of part creation

- Enhanced ability to design for manufacturing

- Reduced productdevelopment-to-production cycle

- More efficient measurement of equipment usage such as overall equipment effectiveness critical manufacturing machines (e.g., vibration, acoustics, temperature, tolerances, and pressure),

- real-time monitoring of product attributes as they move through various stages of the production process

- Reduced scrap

- Enhanced in-process product quality

- Ability to predict machine issues and intervene with preventive maintenance

- Reduced unplanned downtime

- Increased sensor reliability

- Greater visibility and transparency in manufacturing operations

- Reduced costs in factors of production such as capital, labor, energy, and materials from data analysis and efficient production

- Energy reductions, active energy management

- Reduced downtime, increased uptime

- Improved security, reduced risk of Intellectual Property or safety issues

- Reduced integration time

- Freeing up staff time on connectivity and collating data 
Table 1(Cont.). Capabilities, Needs and Potential Impacts

\begin{tabular}{|c|c|c|}
\hline $\begin{array}{l}\text { Smart Manufacturing } \\
\text { Capabilities }\end{array}$ & $\begin{array}{l}\text { Technology Infrastructure } \\
\text { Needed to Support Capabilities }\end{array}$ & $\begin{array}{c}\text { Potential Benefits and Impacts } \\
\text { of Enhanced Technology } \\
\text { Infrastructure }\end{array}$ \\
\hline $\begin{array}{l}\text { Advances in analyzing data } \\
\text { and trends: } \\
\text { - } \quad \text { interpretation and } \\
\text { aggregation of data from } \\
\text { sensing and monitoring } \\
\text { networks, } \\
\text {-Big Data" techniques for } \\
\text { manufacturing, } \\
\text { - } \text { predictive maintenance, } \\
\text { reduction of false } \\
\text { positives, } \\
\text { cloud computing and fee- } \\
\text { for-service cloud-based } \\
\text { algorithms for product } \\
\text { design, simulation, and } \\
\text { manufacturing design }\end{array}$ & $\begin{array}{l}\text { Algorithms to interpret data from } \\
\text { disparate sensors and systems; } \\
\text { definition of important, relevant, } \\
\text { and meaningful data to collect for } \\
\text { predictive maintenance }\end{array}$ & $\begin{array}{l}\text { - } \quad \text { Enproved uptime } \\
\text { - } \quad \text { process quality } \\
\text { - } \quad \text { Reduction of false positives } \\
\text { - Increased overall } \\
\text { equipment effectiveness } \\
\text { - } \begin{array}{l}\text { Better utilization of existing } \\
\text { data sources }\end{array}\end{array}$ \\
\hline $\begin{array}{l}\text { Efficiently communicating } \\
\text { information to decision } \\
\text { makers: } \\
\text { - comprehensive } \\
\text { information interfaces, } \\
\text { human-computer } \\
\text { interaction-based design, } \\
\text { and } \\
\text { easy-to-interpret } \\
\text { interfaces accessible from } \\
\text { any location }\end{array}$ & $\begin{array}{l}\text { Common taxonomy across } \\
\text { platforms and disciplines } \\
\text { Standards in interface design for } \\
\text { manufacturing equipment }\end{array}$ & $\begin{array}{l}\text { - Accelerated development } \\
\text { of interfaces by the private } \\
\text { sector } \\
\text { - More timely, evidence- } \\
\text { based decision making }\end{array}$ \\
\hline $\begin{array}{l}\text { Determining required action } \\
\text { and implementing action: } \\
\text { - real-time feedback of } \\
\text { enhanced sensing and } \\
\text { monitoring data into } \\
\text { factory decision making, } \\
\text { - automated optimization- } \\
\text { based decision making } \\
\text { that functions } \\
\text { independent of human } \\
\text { interaction, } \\
\text { machine-learning } \\
\text { decision-making } \\
\text { algorithms for } \\
\text { manufacturing, and } \\
\text { reconfigurability of } \\
\text { manufacturing systems }\end{array}$ & $\begin{array}{l}\text { Tested and validated decision } \\
\text { models }\end{array}$ & $\begin{array}{l}\text { - Optimized manufacturing } \\
\text { processes } \\
\text { Greater visibility and } \\
\text { transparency in real-time } \\
\text { manufacturing operations }\end{array}$ \\
\hline
\end{tabular}




\section{Key Findings}

The analysis conservatively estimates that meeting the identified needs would save manufacturing companies $\$ 57.4$ billion annually, an approximately 3.2\% reduction in the shop floor cost of production. The estimate is conservative because the quantified benefits do not include impacts such as R\&D cost savings, improved product quality, accelerated development and commercialization of entirely new products, long-term growth and competitiveness impacts and other societal benefits. Respondents indicates these impacts would result from improved smart manufacturing technology infrastructure but they were not able to rigorously quantify these impacts. Further, the benefits of providing the needed technical infrastructure would persist but estimate accounts for impact in a single year. Given this conservative approach, the estimate is particularly impressive.

Second, the analysis finds that investments in public-private manufacturing research consortia and technology extension services may be required to develop and disseminate smart manufacturing technology infrastructure. The study identifies consortia as an import tool for developing critical technology platforms that meet industry specifications. Consortia can also address critical interoperability issues and "bring the multidisciplinary teams together to solve the analysis problems that would advance smart manufacturing." Consortia and public private partnerships aid the implementation of new technology which can be "as much an organizational and cultural challenge as it is a technical challenge." These partnerships and extension services "could also help connect users with developers of smart manufacturing technologies by creating platforms" to transfer and disseminate technology. Consequently, developing and disseminating the technology infrastructure needed to support those platforms will require investments in both consortia and technologyextension services.

The study also demonstrates that uncertainty, risk, network externalities and other barriers to innovation, or market failures ${ }^{3}$, can increase the cost of smart manufacturing R\&D, diminish private investment incentives and increase the importance of public institutions in overcoming these barriers. The barriers exist across a number of the identified needs, because "manufacturers [are] not fully aware or convinced of the benefits, there can be significant technical risk for developers in investing in the required R\&D." Respondents indicated that they "have to learn what the value of that information is and how it can benefit us. At the moment that is all blurry." Given this uncertainty, potential adopters are unwilling to pay for novel features, which in turn diminishes incentive to invest in the technologies. Wireless communications and cloud-based smart manufacturing each present risks to physical and intellectual property. Only by meeting needs for trusted third-party standards and performance data will adopters "know what they are buying at various cost points," be confident in their cyber-physical security and fully compensate developers for their research investments.

Small companies are both key beneficiaries of novel, smart-manufacturing technology infrastructure and critical to realizing its full value. However, the study finds that currently "the cost associated with computing power and analysis software can be significant, and represents a barrier to adoption of smart manufacturing, especially to small and medium enterprises (SMEs)." Novel technology infrastructure that decreased "the cost of software plus the cost of implementation would increase market penetration and adoption of these technologies among SMEs, which could yield substantial economic benefits." Providing the technology infrastructure to enable cloud-based smart manufacturing, for example, "could make big data storage and analytics more accessible for SMEs." 
Further, "a marketplace is needed to encourage startups in this space and related big data application." SMEs stand to benefit as both adopters of smart -manufacturing technology and as providers of smart-manufacturing services. The study identifies potential new business models and public-private partnerships as a potential route to overcome these barriers.

Finally, interviewees indicated that there are critical complementarities across the identified gaps in the technical infrastructure. For example, enhanced sensing capabilities will only add value if they are accompanied by cost-effective and secure transmission of the information. "Similarly, the growth and availability of real-time digital information on manufacturing activities is only as valuable as the ability to analyze the information. Thus, in many ways the value of smart- manufacturing systems is a function of the weakest link in the chain." Consequently, unbalanced investment, closing select technical gaps while leaving other needs unmet, would likely fail to fully realize economic impact.

\section{References}

[1] Anderson G (2013) The Impact of Federally Performed R\&D: Twenty Years of Economic Analysis at the National Institute of Standards and Technology. 2013 Technology Transfer Society Conference.

[2] Gallaher MP, Oliver ZT, Reith KT and O'Connor AC (2016) Economic Analysis of Technology Infrastructure Needs for Advanced Manufacturing: Smart Manufacturing. (NIST, Gaithersburg, MD) NIST GCR 16-007.

[3] Link A Scott J (2011) The theory and practice of public-sector R\&D economic impact analysis. (NIST, Gaithersburg, MD) Planning Report 11-1.

https://www.nist.gov/sites/default/files/documents/director/planning/report11-1.pdf.

[4] Tassey G (2007) The Technology Imperative. (Edward Elgar, Cheltenham).

\footnotetext{
${ }^{1}$ See Gallaher et al. [2].

${ }^{2}$ Technology infrastructure includes infratechnologies and technology platforms. Infratechnologies are technical tools, such as measurement and test methods, reference materials, scientific and engineering databases, process models, and the technical basis for physical and functional interfaces between individual components of both cyber and physical systems technologies. Technology platforms are precompetitive proofs of concept that demonstrate the potential commercial viability of multiple new or improved products, processes, or services. Technology infrastructure shares many common feature with tangible infrastructure. Namely, it is difficult and even undesirable to exclude potential users implementing the technology and usage of the technology infrastructure by a particular organization does not does not preclude others from benefiting to much the same extent. See Anderson [1], Link and Scott [3] and Tassey [4] for a richer discussion of the public good nature of technology infrastructure.

${ }^{3} \mathrm{~A}$ market failure is a situation where free markets do not allocate resources efficiently. In particular, the study finds evidence that market failures such as network externalities, high technical risk, uncertainty and asymmetric information, and economies of scope all impact research in smart manufacturing technology infrastructure. The result is that markets invest too few resources in R\&D.
} 